\title{
Assessing Early Growth and Adiposity: Report from an EarlyNutrition Academy Workshop
}

\author{
Leigh C. Ward $^{\mathrm{a}}$ Lucilla Poston $^{\mathrm{b}}$ Keith M. Godfrey ${ }^{c}$ Berthold Koletzko ${ }^{d}$ \\ on behalf of the EarlyNutrition Academy
}

a School of Chemistry and Molecular Biosciences, The University of Queensland, St Lucia, Brisbane, Qld., Australia; 'Division of Women's Health, Women's Health Academic Centre, King's College London, St Thomas' Hospital, London, and 'MRC Lifecourse Epidemiology Unit and NIHR Southampton Biomedical Research Centre, University of Southampton and University Hospital Southampton NHS Foundation Trust, Southampton, UK, and d Division of Metabolic and Nutritional Medicine, Dr. von Hauner Children's Hospital, University of Munich Medical Centre, Munich, Germany

\section{Key Words}

Adiposity · Anthropometry · Body composition · Body fat distribution $\cdot$ Body mass index $\cdot$ Skinfold thickness

\begin{abstract}
This report provides a summary of a workshop organised by the European Commission-funded EarlyNutrition Project and the EarlyNutrition Academy. Accurate and reliable methods to assess body composition are needed in research on prenatal and early post-natal influences of nutrition on later health because common surrogate measures of maternal and offspring adiposity (body fat content), such as body mass index (BMI), have relatively poor predictive power for the risk of later disease. The key goals of the workshop were to discuss approaches to assess growth and body composition from pregnancy to adolescence, to summarise conclusions and to prepare a framework for research in the EarlyNutrition Project. The participants concluded that there is a pressing need to harmonise the methodologies for assessing body composition, recognising that each has advantages and limitations. Essential core measurements across studies assessing early growth and body composition were iden-
\end{abstract}

\section{KARGER}

E-Mail karger@karger.com

www.karger.com/anm tified, including weight, length, BMI, waist and mid-upper arm circumference, subscapular and triceps skinfold thicknesses, and bioelectrical impedance analysis. In research settings with access to more sophisticated technologies, additional methods could include dual-energy X-ray absorptiometry, peripheral quantitative computed tomography, ultrasound assessment of regional body fat, magnetic resonance imaging (MRI), air displacement plethysmography (ADP), and deuterium dilution. These provide richer data to answer research questions in greater depth but also increase costs. Where overall whole-body composition is the primary outcome measure, ADP or tracer dilution should be used whenever possible. Where regional distribution of body fat is of greater interest, an imaging technique such as MRI is preferred.

Copyright $\odot 2013$ S. Karger AG, Basel

\section{Introduction}

This paper reports on the principal conclusions of a research workshop on the assessment of growth and body composition organised by the EarlyNutrition Project and 
the EarlyNutrition Academy (ENA). The EarlyNutrition Project (www.project-earlynutrition.eu) is a large-scale research project running from 2012 to 2017 with funding from the European Commission's 7th Framework Programme (FP7). This multi-disciplinary collaboration, which focuses on developmental influences on obesity and associated disorders, brings together international leaders in key areas of the developmental programming field located in 12 European countries, the USA and Australia [1]. Work packages include randomised intervention trials in pregnancy and infancy, as well as cohort studies of women before and during pregnancy and their children, which all assess growth and body composition in the mothers and offspring. In addition, the research programme incorporates mechanistic studies in animals, metabolic characterisation of the processes underlying programming and research in placental biology. ENA (www.early-nutrition.org) is a non-profit organisation that was developed in collaboration with several European Commission-supported research projects, including the EarlyNutrition Project, EARNEST, NUTRIMENTHE and EURRECA. The aims are to foster nutrition research, particularly relating to nutrition in women of childbearing age, infants and children, to facilitate research collaboration and to disseminate scientific knowledge in this area of research, in part through organisation of research workshops and position papers [2-5]. Under the auspices of the EarlyNutrition Project and ENA, a workshop was organised in March 2012 that gathered together a multidisciplinary team of experts in the assessment of growth and body composition. The goals of the workshop were to:

- review and critically discuss suitable approaches to assess growth, body composition and adiposity, from pregnancy through to childhood and adolescence,

- summarise conclusions and unresolved challenges in body composition research, and

- prepare a framework for research to be incorporated in the EarlyNutrition Project.

This paper presents a summary of this workshop.

\section{Background}

Overweight and obesity are major health problems worldwide both in children and adults [6]. There is increasing recognition that the progenitors of adult obesity lie in infancy or even in prenatal life [7,8], and childhood obesity itself confers the risk of adult obesity and the associated co-morbidities of related disorders including type 2 diabetes and cardiovascular disease.

Early-Life Body Composition Assessment

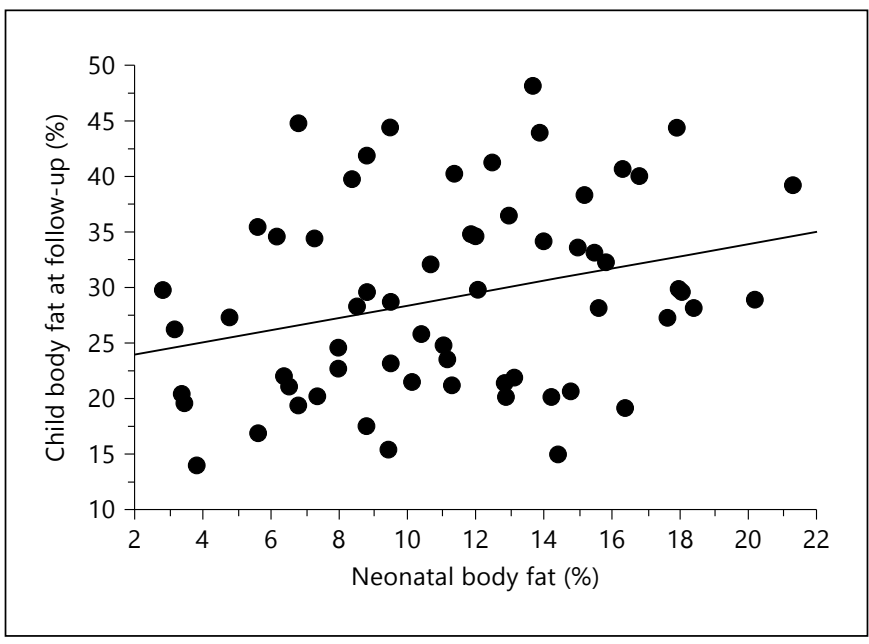

Fig. 1. Neonatal body fat content predicted body fat content in childhood at a mean age of 8.8 years in a prospective cohort study of women without and with gestational diabetes, and their children. $\mathrm{r}=0.29, \mathrm{p}=0.02$. Reproduced with permission from Catalano et al. [11].

\section{Body Composition Predicts Risk}

In adults, body composition is considered a better predictor of health outcome than body weight [9]. Likewise, in children and adolescents, percentage body fat is closely related to chronic disease risk factors, as exemplified in the US National Health and Nutrition Surveys (NHANES III and IV) including data from over 12,000 children and adolescents [10]. Higher percentages of body fat $(>20 \%$ in boys and $>30 \%$ in girls) were associated with cardiovascular disease risk factors (higher blood pressure, lipids and lipoproteins, glucose, insulin and circulating C-reactive protein) and percentage body fat thresholds with a low and a high risk of the metabolic syndrome have been proposed [9]. The optimal body mass index (BMI) percentiles associated with the low-risk percentage body fat threshold were the 83rd and 80th in boys and girls, respectively, while the percentiles associated with the higher risk threshold were the 92nd and 90th, respectively [10]. BMI and percentage body fat derived from skinfolds showed reasonable agreement when used to classify adiposity in children.

Catalano et al. [11] have shown high neonatal body fat content measured by dual-energy X-ray absorptiometry (DXA) to be significantly associated with increased body fat at age 9 years (fig. 1). In turn, pre-gravid maternal obesity, as indicated by pre-gravid BMI, has a significant correlation with neonatal measures of fat mass (FM) or per- 
centage body fat, and with FM in later childhood and adulthood $[12,13]$. The effect appears to be a more important risk factor for increased neonatal adiposity by about twofold than maternal diabetes [14]. Women that are obese at the beginning of pregnancy have fatter and heavier children [15] and there is also evidence for an association between excessive weight gain in pregnancy and increased adiposity in the neonate and child [16]. It is not certain, however, whether these associations reflect a direct relationship between maternal and neonatal FM as few studies have addressed the relationships between the size or distribution of maternal fat depots and offspring fat-free mass (FFM) and FM. Likewise, it is not known if the independent relationships between maternal obesity and excessive gestational weight gain and childhood adiposity reflect direct effects of maternal 'fatness' or more subtle influences of maternal obesity or related dietary factors on pathways of energy balance in the child. There is thus a need for more research into the relationships of maternal fat depot size and distribution with neonatal and childhood FM and related health outcomes. Importantly, an ability to assess the distribution of FM early in pregnancy or to identify reliable surrogate plasma biomarkers may aid in the prediction of adverse pregnancy outcome.

These effects are not limited to children born in the developed countries. The outcomes of the Pune Maternal Nutrition Study have also demonstrated that maternal influences on infant body composition and growth rate during early life are predictive of later outcomes. For example, lower maternal vitamin $B_{12}$ status and smaller mid-upper arm circumference at 6 months of age predicted higher insulin resistance at age 6 years [17].

Although providing strong evidence that maternal nutritional status influences fetal and neonatal body composition, the data which underpin the relationships described are frequently based on surrogate methods for the assessment of body composition. BMI provides a convenient but not entirely accurate estimate of body composition, a problem further compounded in pregnant women by the products of conception and changes in maternal total body water (TBW) and FM to the extent that BMI becomes a useless measure of maternal adiposity after the first trimester. There is increasing recognition that commonly used indices of fatness such as BMI do not adequately capture changes in body composition or adipose tissue distribution that accompany changes in overall adiposity. BMI is correlated with body FM in infants and young children but has relatively poor predictive power for later health and disease risks. This has highlighted the need for accurate and reliable methods to assess body composition from birth through infancy to adolescence and into adulthood.

\section{Problems of Measurement of Body Composition in Neonates and Infants}

Although a large number of methods has been developed or adapted for the measurement of body composition, the assessment of body composition in infants and children presents particular challenges. Both practical and ethical constraints restrict the methods available and their evaluation. In general, methods which involve a significant radiation hazard, e.g. whole-body computed tomography (CT), or are invasive, e.g. tracer dilution techniques that involve repeated blood sampling, are precluded; equally, methods that can safely be undertaken in children [such as total body potassium $\left({ }^{40} \mathrm{~K}\right)$ counting] may not be practical for routine use outside specialist centres. Some techniques that held great promise, e.g. total body electrical conductivity, are no longer possible since the required instrumentation is not currently manufactured. The remaining techniques, principally anthropometry, bioelectrical impedance analysis (BIA), DXA, magnetic resonance imaging (MRI), ultrasound, air displacement plethysmography (ADP), peripheral quantitative CT (pQCT), tracer dilution with non-radioactive tracers and saliva or urine sampling, all have intrinsic advantages and disadvantages. Some are more complex than others, cost varies substantially, subject convenience differs markedly, and the accuracy and precision varies considerably [18] (table 1). In general, there is an inverse relationship between many of these attributes; low-cost, simple-to-use techniques frequently exhibit the lowest accuracy and precision. The task facing researchers is to balance feasibility of technique against cost and accuracy. It is also necessary to define clearly the outcome desired, recognising that this may not be the same at all stages of childhood - neonate, infant, pre-school and school age, and adolescence.

\section{What Is a 'Good' Method?}

Measurement methods may be either indirect, BMI being a good example when used to predict body fat, or direct, e.g. the determination of TBW by tracer dilution which can then be used in an indirect estimation of body fat. Irrespective of whether a technique is direct
Ward/Poston/Godfrey/Koletzko/ on behalf of the EarlyNutrition Academy 
Table 1. Advantages and disadvantages of commonly used technologies for the assessment of body composition

\begin{tabular}{|c|c|c|c|c|c|c|c|}
\hline Impedance & low to high & high & high & low & high & high & low \\
\hline DXA & high & $\begin{array}{l}\text { none to } \\
\text { medium }\end{array}$ & high & low & high & medium & medium \\
\hline $\begin{array}{l}\text { ADP } \\
\text { (e.g. PEA POD, BOD POD) }\end{array}$ & very low & low & $\begin{array}{l}\text { low to } \\
\text { medium }\end{array}$ & medium & low & $\begin{array}{l}\text { medium } \\
\text { to high }\end{array}$ & medium \\
\hline $\begin{array}{l}\text { Imaging } \\
\text { (e.g. ultrasound, MRI) }\end{array}$ & $\begin{array}{l}\text { medium to } \\
\text { very high }\end{array}$ & none & $\begin{array}{l}\text { low to } \\
\text { medium }\end{array}$ & $\begin{array}{l}\text { medium } \\
\text { to high }\end{array}$ & medium & medium & very high \\
\hline
\end{tabular}

or indirect, the method must be shown to be valid by comparison to a reference or 'gold standard' method. Methods may also be cross validated against each other in order to assess interchangeability and allow comparison of results obtained using different techniques. Validation assesses whether a method of measurement produces the correct or true result. Unfortunately, in body composition analysis the 'true' value is rarely known, although it might be possible to validate aspects of any given method, for example the density of fat necessary for densitometric methods of body composition analysis such as PEA POD. Cross validation assesses whether one method produces the same result as another. In the body composition field, most published 'validation' studies are actually cross validation studies. The cautionary note sounded by Parker et al. [19] is worthy of repetition here 'As noted in our paper, the literature is dominated by many studies in which methods of unknown validity are compared against other methods of unknown validity. These studies, although common, are not particularly helpful in that they cannot establish validity of body composition methods, because they do not include a criterion method (multi-component model).' Cross validation may be against an accepted reference method, another field method or between population groups. Ideally, cross validation should always be against a reference method. The consensus of what constitutes a reference method has changed over time as technological advances have opened up opportunities that were previously not possible; notably, the fourcomponent model of body composition

Early-Life Body Composition Assessment weight $=$ fat mass + water + protein + minerals,

is the generally accepted reference method [20], but only became possible with the advent of DXA to quantify bone mineral content.

There is also a need to cross validate in different populations. This is particularly important in a paediatric setting where the density, mineralisation and potassium concentration of the FFM is lower in children than adults and changes progressively as a child matures from infancy to adulthood. Conversely, the water content of the FFM (hydration fraction) is $\geq 10 \%$ higher in preterm infants than in term 3-month-old infants. Accounting for these variables with appropriate validation is particularly important for highly predictive methods such as those using measurements of impedance. While it is crucially important that all methods adopt standardised protocols for their implementation, this is sadly lacking in the body composition arena. Organisations such as the International Atomic Energy Authority are taking a lead here.

It is not always appreciated that cross validation studies can assess only whether the different methods produce the same result. This does not necessarily mean that a 'true' result is provided. Similarly, it is not sufficient to demonstrate a high correlation between results obtained by different methods and to assume that this means that the methods are in agreement or concordant. Appropriate statistical analytic techniques are required. Some journals (e.g. the BMJ group) have admirably taken a lead in requiring that all method comparison stud- 
ies meet acceptable statistical guidelines ['Statistical advice for contributors' http://group.bmj.com/products/ journals/instructions-for-authors/statadvice.pdf].

\section{Body Composition Methods Suitable for Paediatric Use}

Presentations at the ENA workshop covered a wide range of technologies that consortium members were using for body composition assessment. These ranged from classical anthropometric techniques through to sophisticated 3D fetal ultrasound.

\section{Anthropometry}

Anthropometry remains an important aspect of many studies of infant and childhood growth and for monitoring adiposity during pregnancy. Extensive use is being made of anthropometry in the European Childhood Obesity Project study and the Southampton Women's Survey (SWS). In both studies, standardisation and attention to details were applied in the development of standard operating procedures.

The European Childhood Obesity study [21-23] is an intervention study comparing growth in two groups of children that were fed during the 1st year of life with one of two types of formula feeds for infants differing in protein content while preserving energy content. Children exclusively breastfed for at least 3 months are followed as a comparison group. The study is conducted in 11 study sites of 5 European countries. Extensive anthropometric data are collected at inclusion and 3, 6, 12 and 24 months, half yearly until 6 years of age and at the ages of 7.5, 8, 8.5 and 11 years using highly standardised protocols. Particular attention is paid to standardisation and quality control in anthropometric measurements as it has been recognised that it is essential to minimise measurement error and enhance reliability and precision. Considerable efforts have to be undertaken to attain these goals with a main focus on practical teaching and training of anthropometrists. The Childhood Obesity Project study also implements novel statistical approaches to the evaluation of growth data [24-26].

The SWS has been designed to gain insight into perinatal body composition and developmental programming [27]. Over 12,500 non-pregnant women aged 20-34 years living in the city of Southampton have been interviewed, with measurements of pre- and post-natal growth in 3,160 first singleton live births. In the EarlyNutrition project, the children will be studied at the age of 10-11 years.
Anthropometric measurements are based on the methods outlined in the Anthropometric Standardisation Reference Manual [28], which is now out of print, but the recently published Handbook of Growth and Growth Monitoring in Health and Disease [29] represents a suitable alternative.

\section{Ultrasound}

Ultrasound is a technique that bears a low risk, is easy to perform and provides information on localised fat deposition. 2D ultrasound is routinely used in pregnancy to detect congenital anomalies and to assess fetal growth, but obtaining satisfactory images is technically challenging in obese pregnant women, even with the use of tissue harmonic imaging. Obese women are at increased risk of spontaneous abortion and of fetal congenital abnormalities and, later in gestation, the fetus is at increased risk of macrosomia, with implications for later metabolic risk as a result of fetal programming.

Ultrasound is being used in several major studies on pre- and post-natal nutrition to assess growth and body composition. The SWS has utilised a systematic algorithm that combines detailed menstrual data for accurate estimation of gestational age with ultrasound scan data to determine fetal growth trajectories. Deriving standard deviation scores from the 'clouds' or clusters of size measurements at specific gestational ages has posed statistical challenges, and studies in the SWS have shown the potential for systematic biases to be introduced when using some approaches. Using Royston's [30] method has, however, provided an appropriate model for characterising size and growth velocity in utero.

The SWS has also provided the opportunity to investigate the utility of 3D ultrasound in the investigation of maternal influences on fetal body composition, and volumes of the fetal femur, thigh muscle and thigh subcutaneous fat/skin using 3D ultrasound at 34 weeks gestation have been measured. The findings suggest that $3 \mathrm{D}$ ultrasound can provide useful measurements of fetal body composition in late gestation. Fetal femur volume was most strongly associated with the mother's height, fetal thigh muscle volume with the mother's arm muscle area, and fetal subcutaneous fat/skin volume with the mother's sum of skinfold thicknesses.

Later in life, ultrasound is extremely useful in assessing localised or regional fat depots. The Generation R Study Group at the Erasmus Medical Centre has developed a method to assess different measures of abdominal visceral fat by ultrasound in children. Visceral and pre-peritoneal fat thickness and area were well correlated $[0.58(\mathrm{p}<$
Ward/Poston/Godfrey/Koletzko/ on behalf of the EarlyNutrition Academy 
$0.001)$ and $0.76(\mathrm{p}<0.001)$, respectively] with estimates from CT scans [31]. Ultrasound measurements of preperitoneal and subcutaneous fat were also correlated with CT measurements, with correlation coefficients ranging from 0.75 to 0.97 (all $p<0.001$ ). The findings from this validation study suggest that pre-peritoneal fat can be used as an approximation for visceral fat in children and that measuring abdominal fat with ultrasound in children is a valid method for epidemiological and clinical studies. However, the exact, numerical agreement between FM assessed by ultrasound and CT was limited. Therefore, ultrasound should be used with care for obtaining fat distribution measurements in individual children.

Ultrasound was also used to examine the associations of determinants and outcomes with abdominal FM in children within the Generation R Study. This study showed that second-trimester estimated fetal weight was not associated with abdominal subcutaneous FM at the age of 2 years but there were trends towards inverse associations of fetal weight with pre-peritoneal FM. Neither was birth weight associated with measures of abdominal FM at the age of 2 years. However, the study suggested that rapid growth in early post-natal life could be a determinant of later visceral FM as weight gain from birth to the age of 2 years was positively associated with the preperitoneal abdominal FM measures at 2 years [32].

\section{Bioelectrical Impedance Analysis}

BIA works by passing a small electrical current though the body and measuring the impedance to the current. By assuming that the impedance is proportional to the volume of water in the body, it is possible to use BIA to estimate TBW by using a validated prediction equation. Prediction equations are typically based on the impedance index, height $t^{2} / \mathrm{R}$, where $\mathrm{R}$ is the resistance or impedance [33]. The impedance index predicts TBW reasonably well, provided appropriate equations are used [34]. Once TBW has been estimated, FFM and FM can be estimated using the two component model as described below (see measurement of TBW by tracer dilution). The advantages of BIA are that it is a relatively inexpensive and noninvasive way of assessing body composition that is well tolerated by patients and can be performed rapidly and easily at the bedside, without the need for bulky equipment. A disadvantage of BIA is the requirement for population-specific equations for the prediction of TBW, coupled with the need for a hydration coefficient (proportion of the FFM that is water) for FFM that is appropriate for use in the population being studied. Another disadvantage of BIA is that its ability to estimate body

Early-Life Body Composition Assessment composition in terms of FFM and FM will be affected by changes in the subject's hydration status, with FFM being overestimated in oedematous or overhydrated individuals - this is a particular issue in preterm infants who, by comparison with older children or adults, have a high body water content.

BIA has generally been shown to predict accurately TBW in pregnancy, particularly when using equations specific for pregnant women which incorporate additional anthropometry to allow for the changes in body geometry associated with pregnancy [35-38]. Studies in preterm and term infants have shown it to predict TBW accurately [39-41]. However, the rapid fluxes in TBW in preterm and newborn infants mean that its ability to accurately predict body composition in terms of FFM and FM is limited. Several studies have shown that it offers no advantage over standard anthropometry (weight and height) in estimating body composition in infants in the first few weeks or months of life, and even beyond this is subject to significant error [42, 43]. BIA has been shown to correlate highly with measures of TBW obtained using deuterium dilution, and equations have been derived to enable prediction of TBW in children and adolescents. The addition of BIA improved prediction of TBW compared to using anthropometry alone.

One problem that remains to be overcome in order for BIA to be used more widely is the current variety of equipment, approaches and choice of prediction equations for each study population. Standardisation is required to ensure that investigators using this method are using the same approaches in terms of instrumentation, electrode positioning and data analysis, allowing better harmonisation between investigators and comparison between different research groups. Again the International Atomic Energy Authority is taking a lead here [44].

\section{Air Displacement Plethysmography}

The PEA POD infant body composition tracking system (Life Measurement, Concord, Calif., USA) uses ADP and has been developed to measure the percentage body fat of infants [45]. The system is an air displacement plethysmograph in which the naked infant is placed in a closed chamber and air displacement is measured using pressure and volume changes. Body density is derived from measured body mass and the calculated body volume. Measurements of percentage body fat made using the PEA POD have been shown to vary considerably depending on the gestational age at delivery and gender of the infant [46], an observation supported by a carcass analysis validation study using piglets [47]. The method 
has been used successfully to measure body composition in full-term healthy infants at 1 and 12 weeks of age [48]. PEA POD measurement takes only a few minutes to complete but the equipment is not portable and can only measure the body composition in infants with a body weight between 1 and $8 \mathrm{~kg}$. The available data from a limited number of studies evaluating the performance of the method in comparison with other techniques or standards support the conclusion that this method is accurate, reliable and produces reproducible results [49]. A modified version of the adult BOD POD ADP instrument has recently been validated for use in infants and children aged 6-48 months [50].

\section{Magnetic Resonance Imaging}

Quantity and distribution of adiposity in neonates can be studied using MRI. However, image analysis algorithms distinguishing specific fat compartments are lacking. The GUSTO cohort study (http://gusto.sg/about/ gustoinfo.html) has sought to develop a comprehensive analysis programme for segmentation and quantification of abdominal fat in Asian neonates, although this should be applicable to other ethnicities. Analysis methods for MRI data (T1-weighted; 1.5-tesla scanner) collected within 21 days of delivery from an initial group of 387 neonates $\geq 34$ weeks gestation and weight $\geq 2 \mathrm{~kg}$ have been developed. Abdominal fat tissue from the level of the diaphragm to the sacrum was divided into superficial subcutaneous, deep subcutaneous and internal. Volumes of fat tissue $(\mathrm{ml})$ are determined using an in-house MATLAB package comprising automatic processing (watershed transform of local standard deviation, initial identification of superficial subcutaneous and internal compartments) and manual routines. Using these routines, MRI can be used to measure specific fat depots in birth cohort studies. Analysis of neonatal fat depots in the GUSTO cohort is in progress and should provide valuable insights into developmental influences on early-life fat distribution, and their role in metabolic risk observed later in life.

\section{Tracer Dilution}

Measurement of TBW by stable isotope dilution has long been utilised to estimate body composition since it has been demonstrated that a fixed fraction of lean body mass is composed of water. This method relies on the two-component model that divides body weight into FM and FFM (lean body). Deuterium dilution can be used to measure TBW by administering a dose of water labelled with deuterium, and, following equilibration, deuterium enrichment of body water is measured in samples of urine or saliva [51, 52], thereby enabling calculation of lean mass and then, by subtraction, FM. The two-component method is subject to some error due to variation in the composition of FFM. The four-component method of body composition divides body weight into fat, water, mineral and protein. It allows for several assumed constants that are critical for improved accuracy of the twocomponent model. Improvement in the estimates of FFM by deuterium dilution in infants and children has been provided by the generation of new equations that take into consideration age and gender-specific variation constants used to convert measured body constituents into FFM in the two-component models [21]. The use and generation of new equations have been evaluated in several studies [53-56] and these provide useful reference data.

Multi-component models are the most accurate to estimate body composition but due to complexity, cost and ease of use, they are not practical in most settings. Tracer dilution is easy to carry out, acceptable for all ages and requires minimal subject cooperation. It may be ideal for infants and toddlers due to compliance issues with other methods. It is relatively cost effective and can be performed in a non-laboratory setting. The limitations include the need for a biological sample, lack of data on fat distribution and the need for normal hydration. The importance of well-trained staff to instruct parents and administer the dose of deuterium is essential for use in infants and young children. Accuracy in measurement of the dose delivered and collection of samples is necessary to provide the best estimate for body fatness. In healthy subjects, estimation of body fatness using deuterium dilution is relatively accurate and compares well against the 'gold standard' four-component model.

\section{Dual-Energy X-Ray Absorptiometry}

In addition to providing gold standard measurements of bone mineral content, DXA provides an alternative approach to the estimation of both fat and lean mass. The total X-ray dose for neonatal whole-body scans is approximately equivalent to around 1- to 2-day background radiation. Specific paediatric software is required and movement artefact is a potential limitation in infants and children; by swaddling in a standard towel, good quality DXA measurements have, however, been achieved in over 1,000 infants taking part in the SWS $[27,57]$. The accuracy of DXA for the assessment of body composition in small animals has been demonstrated in piglets [58]. DXA has been shown to have good reliability for body
Ward/Poston/Godfrey/Koletzko/ on behalf of the EarlyNutrition Academy 
Table 2. Core body composition measurements recommended for studies of early growth

\begin{tabular}{|c|c|c|c|c|c|c|c|}
\hline & FM & Lean mass & Fat distribution & Cost & Training & Feasibility & All ages \\
\hline Weight & $\mathrm{N} / \mathrm{A}$ & $\mathrm{N} / \mathrm{A}$ & $\mathrm{N} / \mathrm{A}$ & $\$$ & + & +++ & +++ \\
\hline Length & $\mathrm{N} / \mathrm{A}$ & $\mathrm{N} / \mathrm{A}$ & $\mathrm{N} / \mathrm{A}$ & $\$$ & + & +++ & +++ \\
\hline Waist circumference & ++ & $\mathrm{N} / \mathrm{A}$ & ++ & $\$$ & ++ & +++ & ++ \\
\hline MUAC & $(+)$ & + & $\mathrm{N} / \mathrm{A}$ & $\$$ & ++ & +++ & +++ \\
\hline SS & ++ & $\mathrm{N} / \mathrm{A}$ & ++ & $\$ \$$ & +++ & ++ & +++ \\
\hline
\end{tabular}

MUAC = Mid-upper arm circumference; SS/TR = subscapular/triceps skinfold thicknesses; $\$=$ low USD; $\$$ = moderate USD.

composition assessment in newborns and has been suggested as reference technique [59]. While DXA measurements of 'lean' cannot distinguish between the mass of internal organs, newer machines and software are increasingly able to focus on specific body regions.

\section{Peripheral Quantitative Computed Tomography}

The assessment of bone density and geometry has become more and more popular in paediatric research and clinical practice. Around $90 \%$ of bone mass is built up during childhood and adolescence, and the impact of these first 2 decades of life on bone health and risk for osteoporosis is well accepted. There is increasing interest to use pQCT for bone assessment in children and adolescents [60]. This technique can be applied to measure the meta- and diaphysis of long bones (radius, tibia or femur) and only requires a low radiation dose [61, 62]. Despite important advantages over DXA, pQCT is less frequently used. While $\mathrm{pQCT}$ determines true $3 \mathrm{D}$ volumetric bone mineral density, DXA only measures bone mineral content and bone area. Therefore, DXA tends to underestimate bone mineral density in stunted patients and overestimates it in subjects with tall stature [63]. pQCT can also assess the muscle area at the diaphysis. Muscle density is also measured by pQCT, which is important in terms of adiposity-related changes in muscle composition. Data on healthy children and adolescents measured by pQCT are available $[64,65]$.

Despite these advantages, there are still drawbacks that confine the use of pQCT. The site of measurement is limited to radius, tibia or femur. There is a paucity of evidence on the comparability of different devices including software, added to which there is no consensus on the optimal site of measurement, and the placement of the reference line is missing [66].

Early-Life Body Composition Assessment
In conclusion, $\mathrm{pQCT}$ is able to provide important and precise information not only on bone mass but also on bone geometry and its development during childhood and adolescence. However, clinicians and researchers have to consider carefully the challenges and limitations of this technique, and should report all results adequately. Further research is needed to establish valid reference data, to demonstrate the strengths and limitations of different devices, and to give evidence for a rational and consistent analysis protocol.

\section{Consensus Statement on Assessing Early Growth and Adiposity and Research Needs}

There is an over-riding need to harmonise methodologies for the assessment of body composition. All methods have their own advantages and disadvantages (table 2). Needs may vary for different study designs. In a validation study, accuracy is paramount. In intervention studies, precision is more important where comparisons are to be made, while in cohort studies a key requirement is that methods are reliable and repeatable over time. The choice of the method is also governed by feasibility and cost constraints. Nevertheless, a number of essential core measurements across studies can be identified (table 3 ). These relatively low-cost technologies, applicable across all age groups, may provide limited but nonetheless essential information. They are suitable for routine use and it is recommended that they are undertaken in all studies focused on growth and body composition outcomes.

In a research setting, where access to more sophisticated technologies is possible, the scope of available methods broadens (table 3). Use of one or more of these 
Table 3. Body composition techniques for use in a research setting

\begin{tabular}{|c|c|c|c|c|c|c|c|c|c|}
\hline & $\mathrm{FM}$ & $\begin{array}{l}\text { Lean } \\
\text { mass }\end{array}$ & $\begin{array}{l}\text { Fat } \\
\text { distribution }\end{array}$ & $\begin{array}{l}\text { Bone mass/ } \\
\text { density }\end{array}$ & $\begin{array}{l}\text { Liver } \\
\text { volume }\end{array}$ & Costs & Training & Feasibility & $\begin{array}{l}\text { All } \\
\text { ages }\end{array}$ \\
\hline DXA & ++ & ++ & + & ++ & $\mathrm{N} / \mathrm{A}$ & $\$ \$ \$$ & ++ & +++ & $+(+)$ \\
\hline pQCT & $\mathrm{N} / \mathrm{A}$ & + & N/A & +++ & $\mathrm{N} / \mathrm{A}$ & $\$ \$ \$$ & +++ & +++ & $\mathrm{N} / \mathrm{A}$ \\
\hline $\mathrm{CT}$ & + & + & +++ & $(+)$ & ++ & $\$ \$ \$$ & +++ & +++ & $\mathrm{N} / \mathrm{A}$ \\
\hline Ultrasound & $\mathrm{N} / \mathrm{A}$ & $\mathrm{N} / \mathrm{A}$ & ++ & $\mathrm{N} / \mathrm{A}$ & ++ & $\$ \$$ & ++ & ++ & $++(+)$ \\
\hline MRI & +++ & ++ & +++ & $\mathrm{N} / \mathrm{A}$ & +++ & $\$ \$ \$$ & +++ & +++ & $++(+)$ \\
\hline ADP (BOD POD) & +++ & +++ & N/A & $\mathrm{N} / \mathrm{A}$ & N/A & $\$ \$ \$$ & + & ++ & $\mathrm{N} / \mathrm{A}$ \\
\hline Deuterium dilution & + & +++ & N/A & $\mathrm{N} / \mathrm{A}$ & N/A & $\$ \$$ & ++ & ++ & +++ \\
\hline
\end{tabular}

$\$ \$=$ Moderate USD; $\$ \$$ = high USD.

methods provides richer data to answer deeper research questions. Inevitably, there are increased costs associated with their use. It was recommended that, where overall whole-body composition is the primary outcome measure, ADP or tracer dilution be used whenever possible. Where regional distribution of body fat is of greater interest, an imaging technique such as MRI is to be preferred.

\section{Acknowledgements}

The workshop was financially supported in part by the Commission of the European Community, specific RTD Programme 'Quality of Life and Management of Living Resources', within the 7th Framework Programme, research grant No. FP7/2007-13 (EarlyNutrition Project). This paper does not necessarily reflect the views of the Commission and in no way anticipates the future policy in this area. Further support provided by ENA and through unrestricted educational grants from Abbott Nutrition and Danone Research is gratefully acknowledged. K.M.G. is funded by the National Institute for Health Research through the NIHR South- ampton Biomedical Research Centre. The authors kindly acknowledge contributions to the workshop and this paper from C.E. Boeke, P. Catalano, A. Doyle, S. Duggleby, M. Frydenberg, R. Gaillard, M. W. Gillman, V. Grote, V.W.V. Jaddoe, M. Johnson, L. Kenny, B. Marriage, M. van Poppel, D. Rytter, P. Rzehak, P. Taylor and $\mathrm{K}$. Werkstetter.

\section{Disclosure Statement}

L.C.W. has consulted ImpediMed Ltd. K.M.G. has acted as a consultant to Abbott Nutrition and Nestle Nutrition, and has received reimbursement for speaking at an Abbott Nutrition Conference on Pregnancy Nutrition and Later Health Outcomes and at a Nestle Nutrition Institute Workshop. L.P. has received reimbursements for speaking at an Abbott Nutrition Conference on Pregnancy Nutrition and at a Danone Round Table on Prevention of Obesity. K.M.G., L.P. and B.K. participate in a European Commission-funded research consortium with scientific collaboration with Abbott Nutrition, Beneo and Danone Research. None of these commercial entities had any involvement in the conception, execution or preparation of this paper.

\section{References}

1 Koletzko B, Brands B, Poston L, Godfrey K, Demmelmair H, EarlyNutrition Project: Early programming of long-term health. Proc Nutr Soc 2012;71:371-378.

2 Hermoso M, Vollhardt C, Bergmann K, Koletzko B: Critical micronutrients in pregnancy, lactation, and infancy: considerations on vitamin $\mathrm{D}$, folic acid, and iron, and priorities for future research. Ann Nutr Metab 2011;59: 5-9.

3 Koletzko B, Szajewska H, Ashwell M, Shamir R, Aggett P, Baerlocher K, et al: Documentation of functional and clinical effects of infant nutrition: setting the scene for COMMENT. Ann Nutr Metab 2012;60:222-232.
4 Koletzko B, Brands B, Demmelmair H: The Early Nutrition Programming Project (EARNEST): 5 y of successful multidisciplinary collaborative research. Am J Clin Nutr 2011;94: 1749S-1753S.

5 Koletzko B, Bhutta ZA, Cai W, Cruchet S, Guindi ME, Fuchs GJ, et al: Compositional requirements of follow-up formula for use in infancy: recommendations of an international expert group coordinated by the Early $\mathrm{Nu}-$ trition Academy. Ann Nutr Metab 2012;62: 44-54.

6 Waxman A, Norum KR: Why a global strategy on diet, physical activity and health? The growing burden of non-communicable diseases. Public Health Nutr 2004;7:381-383.
7 Patel M, Srinivasan M, Laychock S: Metabolic programming: role of nutrition in the immediate postnatal life. J Inherit Metab Dis 2009; 32:218-228.

$>8$ Tounian P: Programming towards childhood obesity. Ann Nutr Metab 2011;58(suppl 2): 30-41.

9 Thibault R, Genton L, Pichard C: Body composition: why, when and for who? Clin Nutr 2012;31:435-447.

10 Laurson KR, Eisenmann JC, Welk GJ: Body mass index standards based on agreement with health-related body fat. Am J Prev Med 2011;41(suppl 2):S100-S105.
Ward/Poston/Godfrey/Koletzko/ on behalf of the EarlyNutrition Academy 
11 Catalano PM, Farrell K, Thomas A, HustonPresley L, Mencin P, de Mouzon SH, et al: Perinatal risk factors for childhood obesity and metabolic dysregulation. Am J Clin Nutr 2009;90:1303-1313.

12 Reynolds RM, Osmond C, Phillips DI, Godfrey KM: Maternal BMI, parity, and pregnancy weight gain: influences on offspring adiposity in young adulthood. J Clin Endocrinol Metab 2010;95:5365-5369.

13 Gale CR, Javaid MK, Robinson SM, Law CM, Godfrey KM, Cooper C: Maternal size in pregnancy and body composition in children. J Clin Endocrinol Metab 2007;92:3904-3911.

14 Uvena-Celebrezze J, Fung C, Thomas AJ, Hoty A, Huston-Presley L, Amini SB, et al: Relationship of neonatal body composition to maternal glucose control in women with gestational diabetes mellitus. J Matern Fetal Neonatal Med 2002;12:396-401.

$\checkmark 15$ Whitaker RC: Predicting preschooler obesity at birth: the role of maternal obesity in early pregnancy. Pediatrics 2004;114:e29-e36.

-16 Crozier SR, Inskip HM, Godfrey KM, Cooper C, Harvey NC, Cole ZA, et al: Weight gain in pregnancy and childhood body composition: findings from the Southampton Women's Survey. Am J Clin Nutr 2010;91:1745-1751.

-17 Joglekar CV, Fall CH, Deshpande VU, Joshi $\mathrm{N}$, Bhalerao A, Solat V, et al: Newborn size, infant and childhood growth, and body composition and cardiovascular disease risk factors at the age of 6 years: the Pune Maternal Nutrition Study. Int J Obes (Lond) 2007;31: 1534-1544.

18 Lee SY, Gallagher D: Assessment methods in human body composition. Curr Opin Clin Nutr Metab Care 2008;11:566-572.

19 Parker L, Reilly JJ, Slater C, Wells JC, Pitsiladis Y: Validity of six field and laboratory methods for measurement of body composition in boys. Obes Res 2003;11:852-858.

20 Pietrobelli A, Heymsfield SB, Wang ZM, Gallagher D: Multi-component body composition models: recent advances and future directions. Eur J Clin Nutr 2001;55:69-75.

-21 Escribano J, Luque V, Ferre N, Mendez-Riera G, Koletzko B, Grote V, et al: Effect of protein intake and weight gain velocity on body fat mass at 6 months of age: the EU Childhood Obesity Programme. Int J Obes 2012;36:548553.

22 Socha P, Grote V, Gruszfeld D, Janas R, Demmelmair H, Closa-Monasterolo R, et al: Milk protein intake, the metabolic-endocrine response, and growth in infancy: data from a randomized clinical trial. Am J Clin Nutr 2011;94:1776S-1784S.

-23 Koletzko B, von Kries R, Closa R, Escribano J, Scaglioni S, Giovannini M, et al: Lower protein in infant formula is associated with lower weight up to age $2 \mathrm{y}$ : a randomized clinical trial. Am J Clin Nutr 2009;89:1836-1845.

-24 Koletzko B, Beyer J, Brands B, Demmelmair H, Grote V, Haile G, et al: Early influences of nutrition on postnatal growth; in Gillman MW, Gluckman PD, Rosenfeld RG (eds): Re- cent Advances in Growth Research: Nutritional, Molecular and Endocrine Perspectives. Basel, Karger, 2013.

25 Rzehak P, Koletzko S, Koletzko B, Sausenthaler S, Reinhardt D, Grubl A, et al: Growth of infants fed formula rich in canola oil (low erucic acid rapeseed oil). Clin Nutr 2011;30:339345.

26 Rzehak P, Sausenthaler S, Koletzko S, Bauer CP, Schaaf B, von Berg A, et al: Period-specific growth, overweight and modification by breastfeeding in the GINI and LISA birth cohorts up to age 6 years. Eur J Epidemiol 2009; 24:449-467.

27 Inskip HM, Godfrey KM, Robinson SM, Law CM, Barker DJ, Cooper C: Cohort profile: the Southampton Women's Survey. Int J Epidemiol 2006;35:42-48.

28 Lohman TG, Roche AF, Martorell R: Anthropometric Standardization Reference Manual. Champaign, Human Kinetics Books, 1991.

29 Preedy VR: Handbook of Growth and Growth Monitoring in Health and Disease. New York, Springer, 2011.

30 Royston P: Calculation of unconditional and conditional reference intervals for foetal size and growth from longitudinal measurements. Stat Med 1995;14:1417-1436.

31 Mook-Kanamori DO, Holzhauer S, Hollestein LM, Durmus B, Manniesing R, Koek M, et al: Abdominal fat in children measured by ultrasound and computed tomography. Ultrasound Med Biol 2009;35:1938-1946.

- 32 Durmus B, Mook-Kanamori DO, Holzhauer S, Hofman A, van der Beek EM, Boehm G, et al: Growth in foetal life and infancy is associated with abdominal adiposity at the age of 2 years: the generation R study. Clin Endocrinol 2010;72:633-640.

33 Kyle UG, Bosaeus I, De Lorenzo AD, Deurenberg P, Elia M, Gomez JM, et al: Bioelectrical impedance analysis - part I: review of principles and methods. Clin Nutr 2004;23:12261243.

34 Kyle UG, Bosaeus I, De Lorenzo AD, Deurenberg P, Elia M, Manuel Gomez J, et al: Bioelectrical impedance analysis - part II: utilization in clinical practice. Clin Nutr 2004;23:14301453.

35 Lukaski HC, Siders WA, Nielsen EJ, Hall CB: Total body water in pregnancy: assessment by using bioelectrical impedance. Am J Clin Nutr 1994;59:578-585.

36 Van Loan MD, Kopp LE, King JC, Wong WW, Mayclin PL: Fluid changes during pregnancy: use of bioimpedance spectroscopy. J Appl Physiol 1995;78:1037-1042.

37 Lof M, Forsum E: Evaluation of bioimpedance spectroscopy for measurements of body water distribution in healthy women before, during, and after pregnancy. J Appl Physiol 2004;96:967-973

38 Lukaski HC, Hall CB, Siders WA: Assessment of change in hydration in women during pregnancy and postpartum with bioelectrical impedance vectors. Nutrition 2007;23:543550 .
39 Rodriguez G, Ventura P, Samper MP, Moreno L, Sarria A, Perez-Gonzalez JM: Changes in body composition during the initial hours of life in breast-fed healthy term newborns. Biol Neonate 2000;77:12-16.

40 Meio MD, Sichieri R, Soares FV, Moreira ME: Total body water in small- and appropriatefor gestational age newborns. J Perinat Med 2008;36:354-358.

41 Ferreira DM, Souza MN: Bioelectrical impedance spectroscopy for the assessment of body fluid volumes of term neonates. Braz J Med Biol Res 2004;37:1595-1606.

42 Dung NQ, Fusch G, Armbrust S, Jochum F, Fusch C: Body composition of preterm infants measured during the first months of life: bioelectrical impedance provides insignificant additional information compared to anthropometry alone. Eur J Pediatr 2007;166:215-222.

43 Lingwood BE, Storm van Leeuwen AM, Carberry AE, Fitzgerald EC, Callaway LK, Colditz $\mathrm{PB}$, et al: Prediction of fat-free mass and percentage of body fat in neonates using bioelectrical impedance analysis and anthropometric measures: validation against the $\mathrm{PEA}$ POD. Br J Nutr 2012;107:1545-1552.

44 International Atomic Energy Association: Assessment of Body Composition and Total Energy Expenditure in Humans Using Stable Isotope Techniques. Vienna, International Atomic Energy Association, 2009, IAEA Human Health Series 3.

$\checkmark 45$ Ellis KJ, Yao M, Shypailo RJ, Urlando A, Wong WW, Heird WC: Body-composition assessment in infancy: air-displacement plethysmography compared with a reference 4-compartment model. Am J Clin Nutr 2007; 85:90-95.

-46 Hawkes CP, Hourihane JO, Kenny LC, Irvine $\mathrm{AD}$, Kiely M, Murray DM: Gender- and gestational age-specific body fat percentage at birth. Pediatrics 2011;128:e645-e651.

47 Frondas-Chauty A, Louveau I, Le HuerouLuron I, Roze JC, Darmaun D: Air-displacement plethysmography for determining body composition in neonates: validation using live piglets. Pediatr Res 2012;72:26-31.

48 Eriksson B, Lof M, Forsum E: Body composition in full-term healthy infants measured with air displacement plethysmography at 1 and 12 weeks of age. Acta Paediatr 2010;99: 563-568.

49 Li C, McCargar LJ, Casey LM: Infant body composition in the PEA POD ${ }^{\circledR}$ era: what have we learned and where do we go from here? J Dev Origins Health Dis 2013;4:116-120.

50 Rosendale RP, Bartok CJ: Air-displacement plethysmography for the measurement of body composition in children aged 6-48 months. Pediatr Res 2012;71:299-304.

51 International Atomic Energy Association: Introduction to Body Composition Assessment Using the Deuterium Dilution Technique with Analysis of Saliva Samples by Fourier Transform Infrared Spectrometry. Vienna, International Atomic Energy Association, 2011, IAEA Human Health Series 12. 
52 International Atomic Energy Association: Introduction to Body Composition Assessment Using the Deuterium Dilution Technique with Analysis of Urine Samples by Isotope Ratio Mass Spectrometry. Vienna, International Atomic Energy Association, 2011. IAEA Human Health Series 13.

53 Wells JC, Williams JE, Chomtho S, Darch T, Grijalva-Eternod C, Kennedy K, et al: Pediatric reference data for lean tissue properties: density and hydration from age 5 to $20 \mathrm{y}$. Am J Clin Nutr 2010;91:610-618.

54 Wells JC, Fewtrell MS, Davies PS, Williams JE, Coward WA, Cole TJ: Prediction of total body water in infants and children. Arch Dis Child 2005;90:965-971.

55 Butte NF, Hopkinson JM, Wong WW, Smith EO, Ellis KJ: Body composition during the first 2 years of life: an updated reference. Pediatr Res 2000;47:578-585.

56 Bunt JC, Lohman TG, Boileau RA: Impact of total body water fluctuations on estimation of body fat from body density. Med Sci Sports Exerc 1989;21:96-100.
57 Harvey NC, Poole JR, Javaid MK, Dennison EM, Robinson S, Inskip HM, et al: Parental determinants of neonatal body composition. J Clin Endocrinol Metab 2007;92:523-526.

58 Brunton JA, Bayley HS, Atkinson SA: Body composition analysis by dual energy X-ray absorptiometry compared to chemical analysis of fat, lean and bone mass in small piglets. Basic Life Sci 1993;60:157-160.

59 Godang K, Qvigstad E, Voldner N, Isaksen GA, Froslie KF, Notthellen J, et al: Assessing body composition in healthy newborn infants: reliability of dual-energy $\mathrm{x}$-ray absorptiometry. J Clin Densitom 2010;13:151-160.

60 Cole ZA, Harvey NC, Kim M, Ntani G, Robinson SM, Inskip HM, et al: Increased fat mass is associated with increased bone size but reduced volumetric density in pre pubertal children. Bone 2012;50:562-567.

-61 Werkstetter KJ, Ullrich J, Schatz SB, Prell C, Koletzko B, Koletzko S: Lean body mass, physical activity and quality of life in paediatric patients with inflammatory bowel disease and in healthy controls. J Crohns Colitis 2012; 6:665-673.
62 Werkstetter KJ, Pozza SB, Filipiak-Pittroff B, Schatz SB, Prell C, Bufler P, et al: Long-term development of bone geometry and muscle in pediatric inflammatory bowel disease. Am J Gastroenterol 2011;106:988-998.

63 Fewtrell MS: Bone densitometry in children assessed by dual $\mathrm{x}$ ray absorptiometry: uses and pitfalls. Arch Dis Child 2003;88:795-798.

64 Shi L, Libuda L, Schonau E, Frassetto L, Remer T: Long term higher urinary calcium excretion within the normal physiologic range predicts impaired bone status of the proximal radius in healthy children with higher potential renal acid load. Bone 2012;50:1026-1031.

-65 Schonau E, Werhahn E, Schiedermaier U, Mokow E, Schiessl H, Scheidhauer K, et al: Influence of muscle strength on bone strength during childhood and adolescence. Horm Res 1996;45(suppl 1):63-66.

66 Zemel B, Bass S, Binkley T, Ducher G, Macdonald $\mathrm{H}, \mathrm{McKay} \mathrm{H}$, et al: Peripheral quantitative computed tomography in children and adolescents: the 2007 ISCD Pediatric Official Positions. J Clin Densitom 2008;11:59-74. 